Arq. Bras. Med. Vet. Zootec., v.70, n.4, p.1316-1324, 2018

\title{
Estabilidade da caranha em diferentes períodos de armazenamento
}

[Stabilityof the caranhain differentstorage periods]

T.T. Santos, C.R.F. Pires, G.A.S. Martins, A.F.S. Coelho

Universidade Federal do Tocantins - Palmas, TO

\section{RESUMO}

O objetivo deste estudo foi verificar a influência do tempo de armazenamento na qualidade microbiológica, físico-química e sensorial do pescado caranha (Piaractusmesopotamicus). Os pescados foram estocados em gelo durante zero, sete, 14, 21 e 28 dias e submetidos às contagens de microorganismos mesófilos, psicrotróficos, coliformes a $35^{\circ} \mathrm{C}$ e $45^{\circ} \mathrm{C}$, Salmonella sp. e estafilococos coagulase positiva. Foram realizadas análises de temperatura, $\mathrm{pH}$, acidez, bases voláteis, proteínas, lipídeos, cinzas, umidade, prova de cocção, bem como análise sensorial. As contagens de mesófilos, psicrotróficos, coliformes a $35^{\circ} \mathrm{C}$ e $45^{\circ} \mathrm{C}$ aumentaram com o tempo de armazenamento. A presença de Salmonella sp. não foi constatada, enquanto a contagem de estafilococos coagulase positiva foi de <10 (est) UFC/g em todos os períodos de estocagem. Observou-se, ainda, que o tempo de armazenamento apresentou influência em todas as variáveis físico-químicas, exceto para temperatura. $\mathrm{Na}$ análise sensorial, foi constatado um aumento linear do índice de qualidade (IQ) ao longo do armazenamento, e a rejeição ocorreu aos 14 dias.

Palavras-chave: Piaractusmesopotamicus, pescado, vida de prateleira, micro-organismos indicadores

\begin{abstract}
The objective of this study was to verify the influence of storage time on the microbiological, physicalchemical, and sensorial quality of the fish (Piaractusmesopotamicus). The fish were stored on ice for 0, 7, 14, 21, and 28 days and submitted to counts of mesophilic, psychrotrophic, coliform microorganisms at $35^{\circ} \mathrm{C}$ and $45^{\circ} \mathrm{C}$, Salmonella sp. and coagulase positive staphylococci. Analyzes of temperature, pH, acidity, volatile bases, proteins, lipids, ashes, humidity, cooking test, as well as sensorial analysis were performed. Counts of mesophiles, psychrotrophic, coliforms at $35^{\circ} \mathrm{C}$ and $45^{\circ} \mathrm{C}$ increased with storage time. The presence of Salmonella sp. was not observed, whereas the coagulase positive Staphylococcus count was <10 (est) CFU/g in all storage periods. It was also observed that the storage time had influence on all physical-chemical variables, except for temperature. In the sensorial analysis, a linear increase of the quality index $(I Q)$ was verified throughout the storage and the rejection occurred at 14 days.
\end{abstract}

Keywords:Piaractusmesopotamicus, fish, shelflife, indicatormicroorganisms

\section{INTRODUÇÃO}

A caranha(Piaractusmesopotamicus) é um pescado que tem grande aceitação entre a população, em virtude de seu excelente sabor, consistência, coloração branca da carne e facilidade para a obtenção de filés, apresentando um bom potencial para o crescimento na aquicultura nacional (Lima et al., 2012). Essa espécie tem uma alimentação bastante diversificada (Silva e Taddei, 2014): alimenta-se de frutos, sementes e folhas. O Piaractusmesopotamicus é um caracídeo originário da Bacia do Prata, onde é conhecido como pacu, pacu-caranha ou caranha. É um peixe de grande porte, com o corpo robusto e arredondado; apresenta o dorso cinza-escuro e o ventre amarelo-dourado (Souza et al., 2003).

Para avaliar o frescor e a qualidade do pescado, é necessária, além do acompanhamento microbiológico, a avaliação das características

Recebido em 18 de abril de 2016

Aceito 26 de setembro de 2017

E-mail: taisa_ts@hotmail.com 
físico-químicas e sensoriais. Quando se fala em avaliação sensorial da qualidade, o método de índice de qualidade é bastante utilizado, o qual consiste na avaliação dos diversos atributos de qualidade, como aparência, textura, olhos, guelras e abdômen, bem como na modificação desses de acordo com o tempo de estocagem (Gonçalves, 2011).

A vida de prateleira do pescado fresco e/ou refrigerado é relativamente baixa e dependente tanto do manuseio após a captura (ou despesca) quanto do tempo em que ele foi mantido em gelo antes do seu processamento (Ogawa e Maia, 1999). Assim, as informações coletadas pela análise sensorial devem ser somadas aos dados obtidos pelas análises físico-químicas e microbiológicas, pois completarão os dados sobre a qualidade do produto (Gonçalves, 2011).

Mediante o exposto, o objetivo deste estudo foi verificar a influência dos tempos de armazenamento na qualidade microbiológica, físico-química e sensorial do pescado caranha(Piaractusmesopotamicus) armazenado no gelo, em diferentes tempos de estocagem.

\section{MATERIAL E MÉTODOS}

Foi armazenado um total de 15 exemplares do pescado caranha (Piaractusmesopotamicus) e, a cada tempo, três unidades foram escolhidas aleatoriamente para serem utilizadas nas análises. Os pescados, eviscerados e descamados, foram adquiridos de um frigorífico da cidade de Almas/Tocantins, com peso médio de $1 \mathrm{~kg}$. Posteriormente, os exemplares foram lavados em água potável, acondicionados em recipientes com gelo em escama na proporção de 2:1 (quilograma de peixe para quilograma de gelo) e mantidos em caixa isotérmica por 28 dias. Nos tempos zero, sete, 14, 21 e 28 dias, os pescados foram submetidos às análises microbiológicas e físicoquímicas, utilizando-se um delineamento inteiramente ao acaso.

Para o preparo das amostras, a porção correspondente à musculatura foi removida e triturada em moedor tipo Mixer (Versalite, Mondial $\left.{ }^{\circledR}\right)$. O equipamento foi higienizado antes e após ter sido utilizado para cada amostra, a fim de se evitarem possíveis contaminações. Em seguida, as amostras foram homogeneizadas para a realização das análises microbiológicas e físico-químicas.
Retiraram-se $10 \mathrm{~g}$ de unidade analítica das amostras previamente preparadas, as quais foram pesadas em frascos estéreis, procedendo-se, então, à diluição seriada delas até $10^{-3}$ em água peptonada tamponada a $0,1 \%$. Para as análises de Salmonella sp., foram retirados $25 \mathrm{~g}$ de unidade analítica, conforme orientado na literatura. As análises de Salmonella sp., contagem deestafilococos coagulase positiva, contagem de coliformes a $35^{\circ} \mathrm{C}$ (totais) e contagem de coliformes a $45^{\circ} \mathrm{C}$ (termotolerantes), mesófilos, psicrotróficos foram realizadas de acordo com as metodologias descritas por Silva et al. (2010).

Com base na literatura citada, nos testes para coliformes termotolerantes, alíquotas dos tubos de caldo lauril sulfato triptose com produção de gás foram transferidas para tubos com caldo $E$. coli (EC); em seguida, os tubos positivos foram semeados em ágar EMB para uma identificação preliminar de colônias de E. coli. Aquelas que apresentaram características de $E$. coli foram submetidas à coloração Gram e às provas bioquímicas.

As análises de temperatura, $\mathrm{pH}$, acidez titulável, prova de cocção, lipídeos, proteína total, bases nitrogenadas, cinzas e umidade foram realizadas de acordo com as metodologias descritas pelo Instituto Adolfo Lutz (Métodos..., 2008). É importante salientar que as análises físicoquímicas foram feitas em triplicada para cada tempo de armazenamento.

Para a análise sensorial, 15 provadores foram pré-avaliados por meio do teste de reconhecimento de aromas e do teste triangular, selecionando-se, ao final, 11 provadores. Após esses testes, realizaram-se os treinamentos com os pescados, utilizando-se dois exemplares de caranha para cada tempo de armazenamento (zero, sete, 14 e 21 dias). Os atributos sensoriais foram determinados em sessões, em condições de laboratório. As amostras foram retiradas do gelo 30 minutos antes de cada sessão. Por consenso, a equipe selecionou e acrescentou os atributos que deveriam ser listados no protocolo de índice de qualidade (IQ) para a avaliação da qualidade da caranha armazenada no gelo por 21 dias. O protocolo de IQ elaborado apresentou 12 parâmetros de qualidade para a avaliação da caranha armazenada em gelo por 21 dias (Tab. 1). 
Tabela 1. Protocolo do método do índice de qualidade (MIQ) para avaliação sensorial da caranha(Piaractusmesopotamicus) estocada em gelo por 21 dias

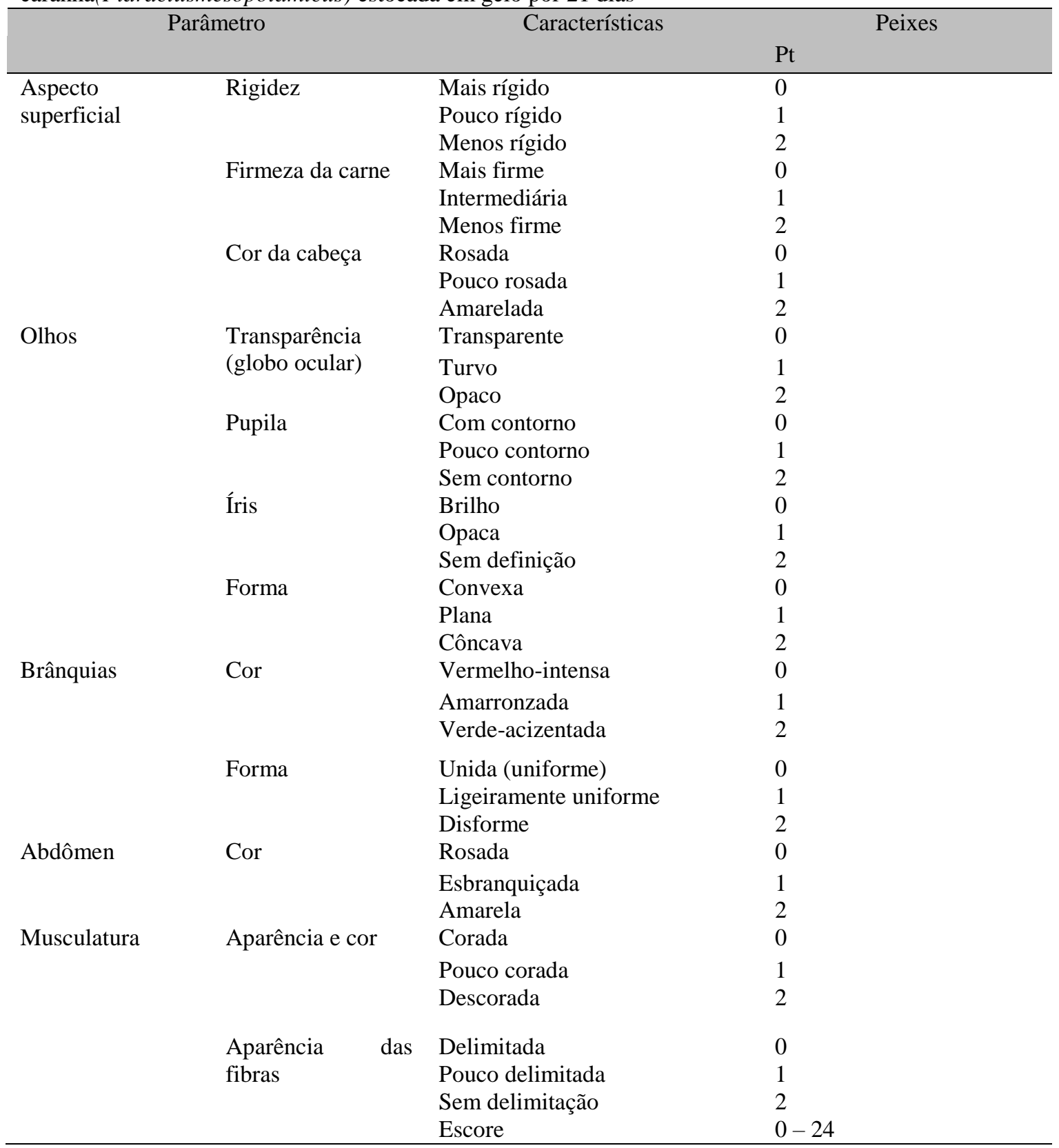

Para a avaliação do índice de qualidade, foram utilizadas seis repetições, para os diferentes tempos de armazenamento e avaliados por cada julgador. $\mathrm{O}$ tempo de armazenamento foi inicialmente projetado em 28 dias, porém o fim do período de estocagem foi determinado quando as amostras receberam a pontuação de IQ máxima para a maioria dos atributos, ocorrendo aos 21 dias de armazenamento.Para a realização da análise sensorial, a qual envolveu a participação de seres humanos, o experimento foi submetido ao Comitê de Ética em Pesquisa da Universidade Federal do Tocantins (219/2013) e previamente aprovado.

Os dados das alterações físico-químicas e sensoriais foram analisados com o auxílio do software SISVAR, por meio da análise de 
variância, seguida do teste $\mathrm{F}$ a $5 \%$ de probabilidade, do teste de Tukey e da análise de regressão. A análise de componentes principais foi realizada com auxílio do programa Chemoface (Nuneset al., 2012).

\section{RESULTADOS E DISCUSSÃO}

No que diz respeito ao número mais provável (NMP) de coliformes a $35^{\circ} \mathrm{C}$, verificou-se uma variação entre 460 e $1100 \mathrm{NMP}^{-1} \mathrm{~g}^{-1}$ nos dias zero e sete de estocagem, e, a partir do $14^{\circ}$ dia de armazenamento, esse valor aumentou para $>1100$. Já em relação aos coliformes a $45^{\circ} \mathrm{C}$, observou-se que, até os 14 dias de estocagem, os pescados apresentavam uma variação de $>3,0$ a 6,2. A partir de 21 dias de estocagem, esse valor aumentou para 6,2 a $27 \mathrm{NMP} \cdot \mathrm{g}^{-1}$. Contudo, em todos os tempos, tais valores estavam de acordo com a legislação, que preconiza até $10^{2} \mathrm{NMP} . \mathrm{g}^{-1}$ para coliformes a $45^{\circ} \mathrm{C}$. Oliveira et al. (2014), em estudo com o pescado pirarucu estocado em gelo por 36 dias, não detectaram o crescimento de bactérias coliformes termotolerantes.

A E. coli é a principal bactéria representante do grupo dos coliformes termotolerantes. É considerada a indicadora mais específica de contaminação fecal recente e da eventual presença de microrganismos patogênicos (Vieira, 2004). No presente estudo, não foi detectada $E$. coli em nenhum dos períodos de armazenamento em gelo, o que indica que não houve contaminação de origem fecal nas amostras analisadas.

Com relação à contagem de estafilococos coagulase positiva, verificou-se que todas as amostras de caranha, analisadas nos cinco tempos de estocagem, estavam de acordo com o padrão estabelecido pela legislação, isto é, máximo $10^{3} \mathrm{UFC}_{\mathrm{g}} \mathrm{g}^{-1}$. Entre as coagulase positivas, o Staphylococcus aureus representa a espécie geralmente envolvida em infecções de humanos, e sua presença está relacionada com falta de higienização por parte de manipuladores de pescado (Vieira, 2004). No presente estudo, não foi detectado esse microrganismo.
Também não foi detectada a presença de Salmonella sp. nas amostras analisadas, em todos os tempos de armazenamento. Esse resultado indica que elas estavam de acordo com a legislação vigente, que preconiza ausência desse microrganismo em $25 \mathrm{~g}$, e que possivelmente os pescados não foram contaminados por esse microrganismo após a pesca. Silva et al. (2008) analisaram 20 amostras de pescado fresco e também não detectaram Salmonella. Foi possível observar que a contagem de bactérias psicrotróficasaumentou a partir do $14^{\circ}$ dia, alcançando contagem próxima de 6log UFC.g. ${ }^{-1}$. Já as bactérias mesófilas alcançaram 5,6log UFC.g ${ }^{-1}$ aos 28 dias, sendo esses os valores maiores encontrados durante a estocagem. Tal fato ocorreu provavelmente em razão da estocagem em gelo, que desfavorece o crescimento desses microrganismos em relação aos psicrotróficos. Resultados semelhantes foram obtidos por Oliveira et al. (2014), que encontraram valores para esses grupos de bactérias próximos a 6log UFC.g ${ }^{-1}$ nos pescados avaliados a partir de 21 dias de armazenamento.

Com relação às análises físico-químicas, a Tab. 2 apresenta os valores médios e o desvio-padrão das análises físico-químicas realizadas para o pescado caranha durante o armazenamento em gelo.

Observou-se que o $\mathrm{pH}$ não variou significativamente $(\mathrm{P}<0,05)$ entre zero e sete dias de armazenamento e entre os dias 14 e 21 (Tab. 2), porém houve alteração significativa ao final do período de estocagem. Os valores de $\mathrm{pH}$ variaram entre 6,26 e 6,83 ao longo dos 28 dias de armazenamento, sendo mantidos os valores de $\mathrm{pH}$ dentro do limite estabelecido pela legislação $(6,70)$ até 21 dias de armazenamento (Brasil, 1997).

Para acidez, não houve mudança significativa a partir de 14 dias de armazenamento. A acidez é consideravelmente menor em peixes, e o ácido predominante é o láctico, sendo a análise de acidez um parâmetro importante para indicação da produção de ácido por bactérias deteriorantes (Cecchi, 2003). 
Tabela 2.Características físico-químicas da caranha (Piaractusmesopotamicus) eviscerada e armazenada em gelo em diferentes tempos de estocagem

\begin{tabular}{cccccc} 
Característica & Média \pm DP & Média \pm DP & Média \pm DP & Média \pm DP & Média \pm DP \\
\cline { 2 - 6 } & 0 & 7 & 14 & 21 & 28 \\
\hline pH & $6.26 \pm 1,14 \mathrm{c}$ & $6.28 \pm 0,95 \mathrm{c}$ & $6.59_{ \pm} 0,67 \mathrm{~b}$ & $6.66 \pm 0,80 \mathrm{~b}$ & $6.83 \pm 1,33 \mathrm{a}$ \\
Acidez & $0.08_{ \pm} 0,01 \mathrm{a}$ & $0.07_{ \pm} 0,01 \mathrm{~b}$ & $0.03_{ \pm} 0,005 \mathrm{c}$ & $0.03_{ \pm} 0,005 \mathrm{c}$ & $0.0{ }_{ \pm} 0,005 \mathrm{c}$ \\
Umidade & $75.80 \pm 1,14 \mathrm{ab}$ & $74.45_{ \pm} 0,9 \mathrm{bc}$ & $76.39_{ \pm} 0,6 \mathrm{ab}$ & $78.44 \pm 0,8 \mathrm{a}$ & $72.78 \pm 1,34 \mathrm{c}$ \\
BVN & $5.69 \pm 0,31 \mathrm{~d}$ & $8.08_{ \pm} 0,35 \mathrm{~cd}$ & $8.45_{ \pm} \pm, 43 \mathrm{c}$ & $25.64 \pm 0,73 \mathrm{~b}$ & $29.71 \pm 1,7 \mathrm{a}$ \\
Proteína & $11.34 \pm 0,44 \mathrm{a}$ & $10.70 \pm 0,18 \mathrm{ab}$ & $10.33 \pm 0,28 \mathrm{ab}$ & $10.28 \pm 0,34 \mathrm{~b}$ & $9.04 \pm 0,53 \mathrm{c}$ \\
Temperatura & $0.56 \pm 0,11 \mathrm{a}$ & $0.60 \pm 0,11 \mathrm{a}$ & $0.54 \pm 0,05 \mathrm{a}$ & $0.73 \pm 0,05 \mathrm{a}$ & $0.60 \pm 0,10 \mathrm{a}$ \\
Lipídeos & $1.58 \pm 0,07 \mathrm{~b}$ & $1.70 \pm 0,10 \mathrm{~b}$ & $1.60 \pm 0,14 \mathrm{~b}$ & $1.60 \pm 0,02 \mathrm{~b}$ & $2.14 \pm 0,13 \mathrm{a}$ \\
Cinzas & $0,93 \pm 0,03 \mathrm{a}$ & $0,71 \pm 0,01 \mathrm{~b}$ & $0,61 \pm 0,03 \mathrm{c}$ & $0,53 \pm 0,01 \mathrm{~d}$ & $0,46 \pm 0,03 \mathrm{e}$
\end{tabular}

Médias seguidas por letras iguais, na mesma linha, não diferem significativamente entre si ao nível de $95 \%$ de confiança $(\mathrm{P} \leq 0,05)$.

Ainda em relação à Tab. 2 observa-se que a umidade não variou significativamente até 14 dias de estocagem. Já em relação aos lipídeos, verificou-se diferença significativa entre as médias das amostras apenas aos 28 dias de estocagem. Segundo Ogawa e Maia (1999), o conteúdo de umidade dos peixes, em geral, está em torno de $80 \%$, variando inversamente com o teor de lipídeos. Além disso, outra explicação plausível para as variações dos teores de lipídeos é a de essas biomoléculas apresentam maior variação em função do tipo de músculo corporal em uma mesma espécie, sexo, idade, habitat e dieta, entre outros fatores.

No estudo realizado por Oliveira et al. (2014), os valores médios da composição centesimal encontrados para o pescado pirarucu, também estocado em gelo, bem como a média para proteína, lipídeos, cinzas e umidade, foram, respectivamente, $17,56 \%, 0,62 \%, 0,87 \%$ e $79,51 \%$. Resultados semelhantes foram observados para a caranha, no entanto o pescado pirarucu, com base nesses dados, é mais proteico e apresenta um teor maior de lipídeos; já em relação a cinzas, os valores médios encontrados assemelharam-se aos observados no presente estudo (Oliveira et al., 2014).
O teor de proteína apresentou diferença significativa entre as amostras apenas aos 28 dias de estocagem (Tab. 2). Essa mudança pode ser explicada pelo fato de as proteínas do pescado serem mais instáveis do que as dos organismos terrestres e desnaturarem-se com maior facilidade, em especial quando expostas a alterações de pH (Ogawa e Maia 1999), fato ocorrido neste estudo, pois, aos 28 dias de armazenamento, também ocorreram alterações nos valores de $\mathrm{pH}$.

Em relação a cinzas, ocorreu uma diferença significativa em todos os dias de estocagem. A determinação de cinzas indica a riqueza da amostra em termos de elementos minerais (Fogaça et al., 2009). Os teores de cinzas nos peixes de água doce apresentam variações que vão de 0,1 a 3,3\% (Contreras-Guzmán, 1994). Essa diferença no conteúdo de minerais ocorre devido ao estado em que o peixe é analisado, ou seja, se é analisado inteiro, com ou sem as "espinhas" ou com ou sem a pele (Borgstrom, 1962; Kirschnik, 2007), sendo uma parte dos minerais presentes nos pescados encontrada no estado inorgânico, ligada a proteínas, lipídeos e açúcares (Gonçalves, 2011). Os valores de cinzas encontrados neste estudo ficaram dentro dos valores citados na literatura. 
A temperatura foi o único parâmetro que não variou significativamente de acordo com o teste de $\mathrm{F}(\mathrm{P}>0,05)$ durante a avaliação da vida útil de caranha eviscerada e armazenada em gelo. De acordo com Ozogulet al. (2005), para manter a contagem total de bactérias o mais baixo possível, a temperatura de armazenamento em gelo do produto deve se manter baixa. A temperatura dos pescados durante a estocagem manteve-se dentro do padrão federal, que exige temperaturas menores que $5^{\circ} \mathrm{C}$ (Brasil, 2001).

Quando se trata da acidez total e BVN, os valores variaram entre 0,03 e $0,08 \%$, para acidez, e entre 5,70 e 29,70 N-BVT/100, para BVN. Borges et al. (2013), em um estudo para a determinação de vida de prateleira do pescado pacu, durante os 17 dias de armazenamento em gelo, encontraram valores médios de BVN e acidez variando entre 8,82 e $18,90 \mathrm{~N}-\mathrm{BVT} / 100 \mathrm{~g}$ e entre 0,01 e $0,09 \%$, respectivamente. No presente estudo, trabalhou-se com 28 dias de estocagem e observou-se que os valores de BVN foram superiores aos apresentados pelos autores, o que pode ser justificado pela ação enzimática e bacteriana decorrente da deterioração durante o armazenamento sob refrigeração, que promove a formação de compostos nitrogenados (Gonçalves, 2011), uma vez que, a partir dos 21 dias de estocagem, ocorreu um aumento na contagem de bactérias psicrotróficas.
Já em relação à análise sensorial, as pontuações médias obtidas da equipe previamente treinada, formada por 11 julgadores, em seis repetições por julgador, levantados a partir da aplicação do MIQ para a caranha eviscerada e armazenada em gelo, estão dispostas na Tab. 3 .

Tabela 3. Médias e desvio-padrão dos escores, em escala de 0 a 24, resultantes da aplicação do método de índice de qualidade (MIQ) da caranha (Piaractusmesopotamicus) eviscerada e estocada em gelo durante 21 dias

\begin{tabular}{cc}
\hline $\begin{array}{c}\text { Tempo de } \\
\text { armazenamento (dias) }\end{array}$ & Escore \\
\hline 0 & $0,13 \pm 0,35$ \\
7 dias & $11,78 \pm 0,98$ \\
14 dias & $17,29 \pm 2,17$ \\
21 dias & $21,66 \pm 1,54$ \\
\hline
\end{tabular}

A soma dos escores atribuídos a cada característica sensorial em cada dia de estocagem permitiu a construção da curva de calibração do método de índice de qualidade, apresentada na Fig. 1, em que se observam valores de IQ mínimo e máximo de 0,13 e 21,66, respectivamente. O IQ da caranha apresentou um comportamento linear estatisticamente significativo $(\mathrm{P}<0,05)$.

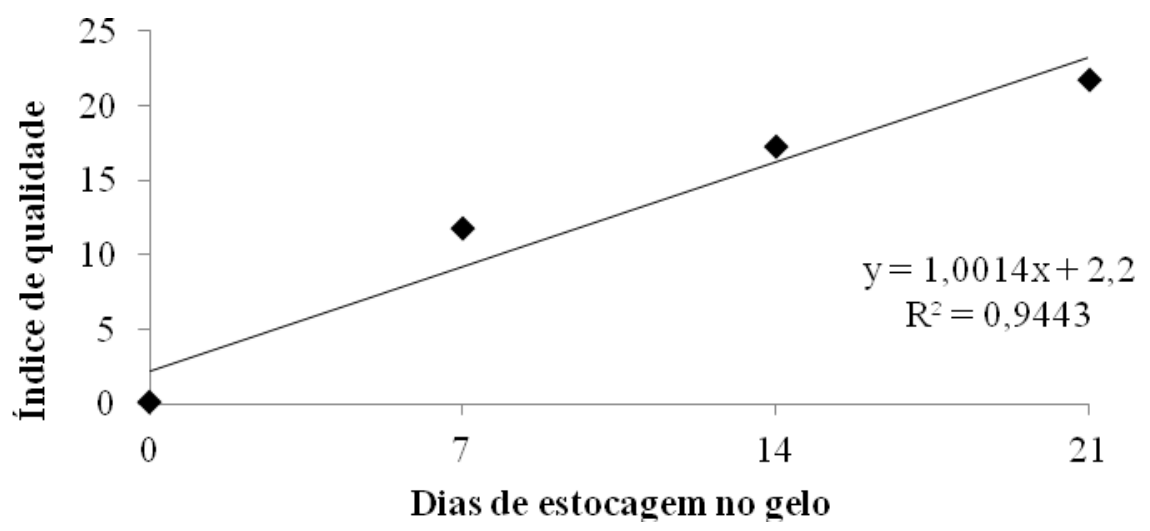

Figura 1. Curva de calibração do método de índice de qualidade de caranha eviscerada e estocada em gelo por 21 dias.

Na presente investigação, o IQ médio aumentou do dia zero para o sétimo dia de armazenamento, porém a rejeição ocorreu aos 14 dias, quando o pescado atingiu 17 pontos de demérito. As médias dos escores de 14 e 21 dias de estocagem, entretanto, ficaram menos distantes (Tab. 3 e Fig. 1), o que demonstra que, a partir do $14^{\circ}$ dia de estocagem, ficou mais difícil para os julgadores diferenciarem as amostras de 14 e 21 dias, pois as alterações sensoriais mais 
importantes na caranha ocorreram durante este período de estocagem, fato que evidencia o ápice da deterioração do pescado. É perceptível, ainda, que os julgadores estavam em maior consenso ao analisarem a caranha fresca com o protocolo MIQ no início do armazenamento, em comparação com o pescado que não estava mais fresco.

No estudo realizado por Soares e Gonçalves (2012), com tilápia-do-nilo estocada em gelo, também foi encontrada uma equação linear e o IQ variou de zero a 14 pontos. A mudança mais intensa ocorreu do sexto para o nono dia de estocagem. Nesse período, o IQ médio aumentou de 5,33 para 8,66. O IQ de rejeição para o filé foi de 12 pontos, atingidos aos 15 dias em gelo; e ainda aos 18 dias em gelo, os filés estavam completamente deteriorados, atingindo a máxima pontuação do esquema MIQ, 14 pontos.

O atributo de qualidade aspecto superficial mostrou que, no sétimo dia de estocagem, o pescado já apresentava diferença significativa em relação ao pescado do dia inicial, pois apresentou uma perda da rigidez e firmeza da carne com o decorrer dos dias de estocagem. Observou-se que não houve diferença na perda de firmeza do pescado com 14 e 21 dias de armazenamento. No protocolo sensorial para avaliação da corvina (Micropogoniasfurnieri), foi apresentado um declínio na rigidez da carne entre o sétimo e o $10^{\circ}$ dia de estocagem em gelo (Teixeira et al., 2009). No presente estudo, a caranha começou a apresentar uma menor rigidez e firmeza da carne, bem como alteração da cor da cabeça, aos 14 dias de estocagem em gelo.

Ao se avaliarem as características dos olhos, observaram-se quatro atributos: transparência do globo ocular, pupila, íris e forma dos olhos. O globo ocular apresentou-se límpido até aproximadamente o sétimo dia de estocagem, quando começou a tornar-se turvo a partir do $14^{\circ}$ dia; não houve diferença significativa entre os pescados armazenados por 14 e 21 dias quanto aos parâmetros pupila e íris. A forma dos olhos se alterou de maneira mais acentuada a partir do $14^{\circ}$ dia de estocagem. A evolução dos atributos dos olhos ocorreu de modo muito semelhante na corvina (Micropogoniasfurnieri), de acordo com o trabalho realizado por Teixeira et al. (2009).
O parâmetro brânquias foi avaliado por dois atributos: cor e forma. A cor, inicialmente vermelho-vivo, ao final do período de armazenamento, apresentou uma coloração mais esverdeada. Não houve diferença na forma das brânquias a partir de 14 dias de armazenamento. Para sardinhas verdadeiras no período inicial de estocagem, as brânquias das amostras mostravam-se com coloração vermelho-vinho e cheiro de alga (Andrade et al., 2012), dados semelhantes aos encontrados para o pescado caranha no tempo inicial de estocagem em gelo.

A cor da musculatura, do abdômen e o formato das fibras da musculatura apresentaram uma evolução semelhante, ocorrendo alterações de forma regular até o $14^{\circ}$ dia de armazenamento. No estudo realizado por Soares e Gonçalves (2012) com tilápia-do- nilo estocada em gelo, aos 18 dias de armazenamento, a musculatura do pescado estava completamente mole, autolisada. Esses dados são semelhantes aos encontrados no presente estudo, uma vez que, aos 21 dias, a caranha apresentava-se mole, com musculatura e abdômen opacos e com as fibras sem delimitação.

Os parâmetros de qualidade foram transformados em uma representação gráfica por meio da análise de componentes principais (ACP), utilizando-se os escores médios dos atributos sensoriais obtidos no índice de qualidade. A ACP permitiu observar quais atributos melhor caracterizaram as mudanças na qualidade da caranha, por meio de um gráfico de dispersão tridimensional.A Fig. 2 mostra o comportamento das amostras nos diferentes tempos de armazenamento. $\mathrm{Na} \mathrm{ACP}, \mathrm{o}$ primeiro componente principal (CP1) explicou 97,41\% da variabilidade total, o segundo componente principal (CP2) explicou $1,76 \%$ da variância do conjunto de dados. Os dois primeiros componentes principais explicaram $99,17 \%$ da variação ocorrida entre as amostras.

Com base na análise de componentes principais dos atributos de qualidade do MIQ de caranha, é possível observar a formação de três grupos: o primeiro contendo as amostras do tempo inicial (dia zero), o segundo com as amostras com sete dias de armazenamento e o terceiro com as amostras com 14 e 21 dias de armazenamento. Os atributos que mais contribuíram para a diferenciação das amostras em ordem de 
importância foram cor das brânquias $(\mathrm{P}=$ 0,0002); forma dos olhos ( $\mathrm{P}=0,0007)$; cor da musculatura $(\mathrm{P}=0,0012)$; rigidez $(\mathrm{P}=0,0022)$; transparência dos olhos $(\mathrm{P}=0,0043)$; pupila $(\mathrm{P}=$ 0,0139); firmeza $(\mathrm{P}=0,0269)$; forma das brânquias $(\mathrm{P}=0,0322)$.

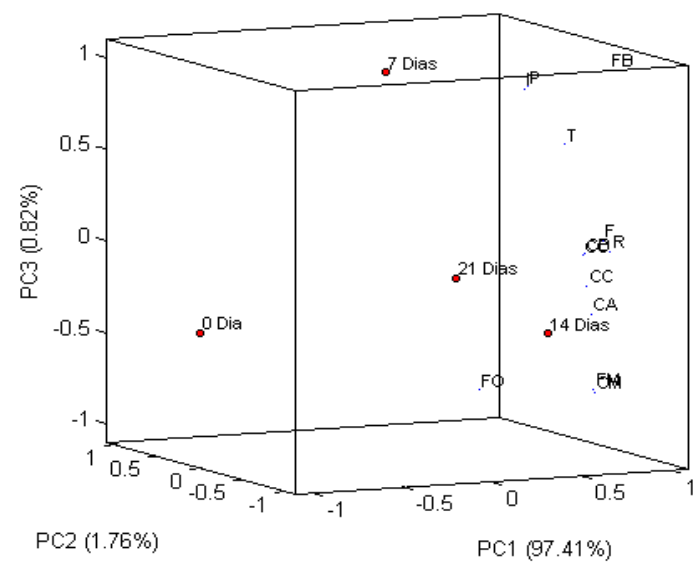

Figura 2. Análise de componentes principais dos termos descritores do método de índice de qualidade (MIQ) da caranha (Piaractusmesopotamicus) armazenada no gelo por 21 dias. 'R=rigidez', ' $\mathrm{F}=$ =firmeza', 'T=transparência dos olhos', 'P=pupila','I=íris', 'FO=forma dos olhos', 'CB=cor das brânquias', 'FB=forma das brânquias', 'CM=cor da musculatura', 'FM=fibras da musculatura', 'CC=cor da cabeça'.

Para o pescado corvina (Teixeiraet al., 2009), a ACP revelou que os atributos aspecto superficial e odor das brânquias se destacaram dos demais, seguidos pelos atributos transparência do globo ocular e pupila, o que indica que foram relevantes indicadores de frescor das corvinas estudadas. Em comparação com o estudo aqui descrito, os parâmetros transparência do olho e pupila também foram importantes para a diferenciação das amostras quanto ao tempo de estocagem em gelo.

Ao se realizar uma comparação entre as análises microbiológicas, físico-químicas e sensorial, a vida útil do pescado caranha estocado em gelo é de 14 dias, pois, com as alterações nesse tempo de estocagem, os pescados começaram a ser rejeitados. Com 21 dias de estocagem, tornam-se mais evidentes as alterações nos pescados, ocorrendo a rejeição total da caranha. Esse tempo foi maior que o dos peixes Sepiiaofficinalis
(Vaz-pires e Seixas 2006) e sardinha (Sardinellabrasiliensis) (Silva et al., 2010), que foi de 10 dias.

\section{CONCLUSÃO}

Com base nos resultados das análises microbiológicas, físico-químicas e sensorial, conclui-se que a caranha (Piaractusmesopotamicus) eviscerada e armazenada em gelo mantém as características adequadas para o consumo humano até 14 dias. Além disso,, é possível constatar que o esquema MIQ desenvolvido para esse pescado foi eficaz para avaliar seu frescor e estimar sua vida útil.

\section{REFERÊNCIAS}

ANDRADE, S.C.S.; MÁRSICO, E.T.;FRANCO, R.M.et al. Validade comercial de sardinhas inteiras e refrigeradas avaliada por análises físico químicas, bacteriológicas e sensorial. Ciênc. Rural, v.42, p.1901-1907, 2012.

BORGES, A.; CONTE-JUNIOR, C.A.; FRANCO, R.M. et al. Quality Index Method (QIM) developed for pacu (Piaractusmesopotamicus) and determination of its shelf life. Food Res. Int., v.54, p.311-317, 2013.

BORGSTROM, G. Fish as food. New York: Academic Pess, 1962. v.2.

BRASIL. Agência Nacional de Vigilância Sanitária do Ministério da Saúde. Regulamento Técnico Sobre Padrões Microbiológicos para Alimentos, 2001.Diário Oficial da União, Brasília, 2001

BRASIL. Ministério da Agricultura, Pecuária e Abastecimento. Regulamento da inspeção industriale sanitária de produtos de origem animal, 1997. Diário Oficial da União, Brasília, 1997

CECCHI, H.M. Fundamentos teóricos e práticos em análise de alimentos. 2.ed. São Paulo: Unicamp, 2003. 207p.

CONTRERAS-GUZMÁN, E.S. Bioquímica de pescados e derivados. Jaboticabal: Funep, 1994. $409 \mathrm{p}$.

FOGAÇA, F.H.S.; LEGAT, A.P.; PEREIRA,A.M.L. et al. Métodos para análise de pescados. Teresina: Embrapa, 2009. 39p. 
GONÇALVES, A.A. Tecnologia do pescado: ciência, tecnologia, inovação e legislação. São Paulo: Atheneu, 2011. 624p.

KIRSCHNIK, P.G. Avaliação da estabilidade de produtos obtidos de carne mecanicamente separada de tilápia nilótica (Oreochromisniloticus). 2007. 102f. Tese (Doutorado em Aqüicultura) - Centro de Aquicultura, Universidade Estadual Paulista, Jaboticabal, S.P.

LIMA, M.M.; MUJICA, P.I.C.; LIMA, A.M. Caracterização química e avaliação do rendimento em filés de caranha (Piaractusmesopotamicus). Braz. J. FoodTechnol., v.15, p.41-46, 2012.

MÉTODOS físico-químicos para análise de alimentos. São Paulo: Instituto Adolfo Lutz, 2008. 1020p.

NUNES, C.A.; FREITAS, M.P.; PINHEIRO, A.C.M. et al. Chemoface: a novel free userfriendly interface for chemometrics. J. Braz. Chem. Soc., v.23, p.2003-2010, 2012.

OGAWA, M.; MAIA, E.L. Manual da pesca: ciência e tecnologia do pescado. São Paulo: Varela, 1999. 430p.

OLIVEIRA, P.R.; JESUS, R.S.; BATISTA, G.M. et al. Avaliação sensorial, físico-química e microbiológica do pirarucu (Arapaima gigas, Schinz 1822) durante estocagem em gelo.Braz. J. Food Technol., v.17, p.67-74, 2014.

OZOGUL, Y.; OZOGUL, F.; GULSUN, O. et al. Freshness assessment of European eel (Anguilla anguilla) by sensory, chemical and microbiological methods. FoodChem., v.92, p.745-751, 2005.

SILVA, M.L.; MATTÉ, G.R.; MATTÉ, M.H. Aspectos sanitários da comercialização de pescado em feiras livres da cidade de São Paulo, SP/Brasil. Rev. Inst. Adolfo Lutz, v.67, p.208214, 2008.
SILVA, N.; JUNQUEIRA, V.C.A.; SILVEIRA, N.F.A. et al. Manual de métodos de análise microbiológica de alimentos. 3.ed. São Paulo: Varela, 2010. 624p.

SILVA, T.E.; TADDEI, F.G. Predação de ovócitos de Piaractusmesopotamicus (pacucaranha) por Macrobrachiumamazonicum em condições laboratoriais. Bol. Inst. Pesca, v.40, p.207-214, 2014.

SOARES, K.M.P.; GONÇALVES, A.A. Aplicação do método do índice de qualidade (MIQ) para o estudo da vida útil de filés de tilápia do Nilo (Oreochromisniloticus) sem pele, armazenados em gelo. Rev. Semin. Ciênc. Agrár., v.33, p.2289-2300, 2012.

SOUZA, M.L.R.; GANECO, L.N.; NAKAGHI, L.S.O. et al. Histologia da pele do pacu (Piaractusmesopotamicus) e testes de resistência do couro. Acta Sci. Anim. Sci., v.25, p.37-44, 2003.

TEIXEIRA, M.S.; BORGES, A.; FRANCO, R.M. et al. Método de índice de qualidade (QIM): desenvolvimento de um protocolo sensorial para corvina (Micropogoniasfurnieri).Rev. Bras. Ciênc. Vet., v.2, p.83-88, 2009.

VAZ-PIRES, P.; SEIXAS, P. Development of new quality index method (QIM) schemes for cuttlefish (Sepia officinalis) and broadtail shortfin squid (Illexcoindetii). FoodControl., v.17, p.942-949, 2006.

VIEIRA, R.H.S.F. Microbiologia, higiene $e$ qualidade do pescado: teoria e prática. São Paulo: Varela, 2004. 380p. 